
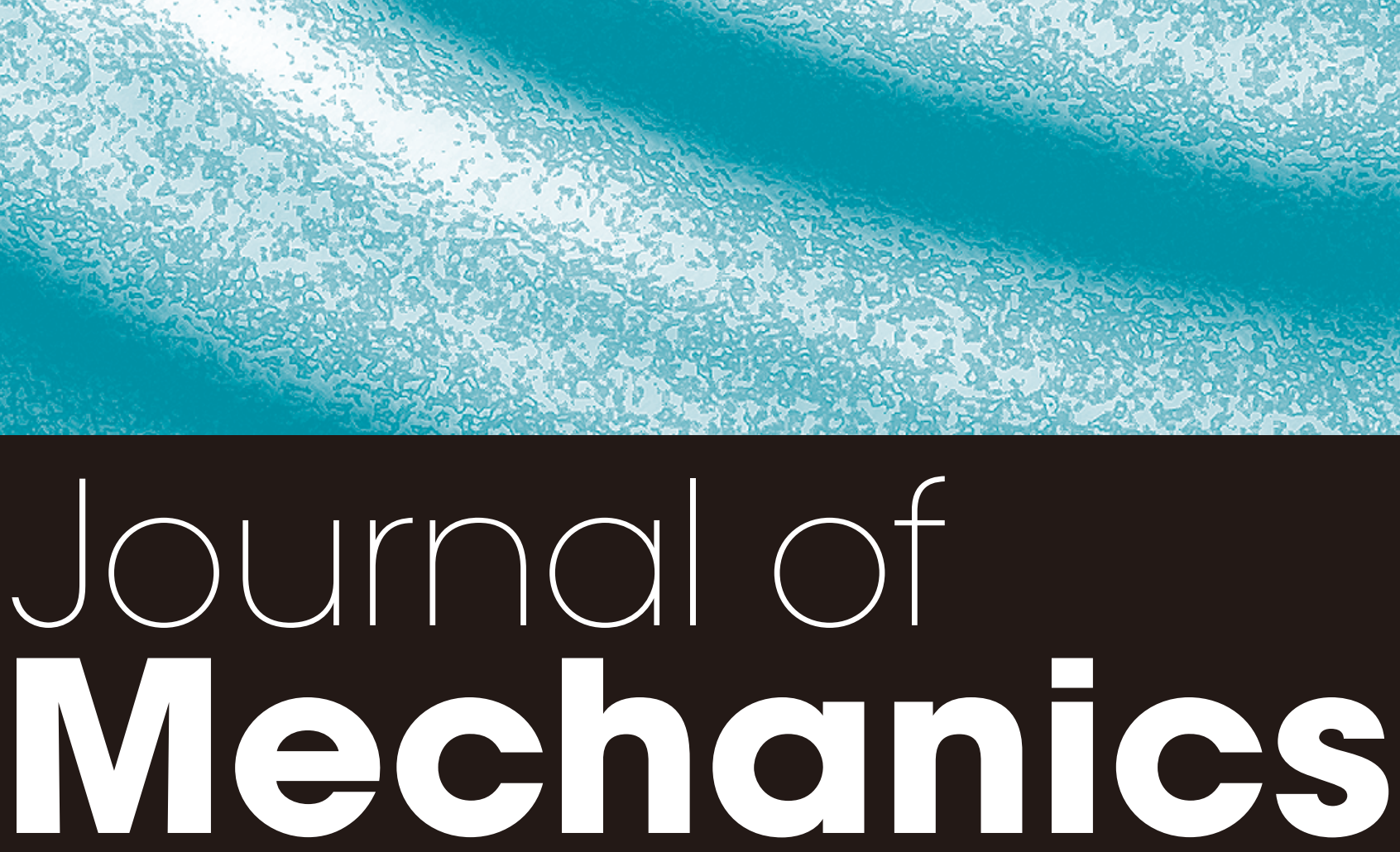

Volume 31 Issue 2 April 2015 


\title{
Journal of Mechanics
}

\begin{abstract}
Aims and Scope:
The objective of the Journal of Mechanics is to provide an international forum to foster exchange of ideas among mechanics communities in different parts of world. The Journal of Mechanics publishes original research in all fields of theoretical and applied mechanics. The Journal especially welcomes papers that are related to recent technological advances, such as micro/nanomechanics, medical and biological systems, and microscale heat transfer. The contributions, which may be analytical, experimental or numerical, should be of significance to the progress of mechanics. Papers which are merely illustrations of established principles and procedures will generally not be accepted. Reports that are of technical interest are published as Short articles. Review articles are published only by invitation.
\end{abstract}

Editor-in-Chief and Chairman of Editorial Board:

K. N. Chiang, Department of Power Mechanical Engineering, National Tsing Hua University, Hsinchu, Taiwan

\section{Associate Editors:}

C. Bailey, Mathematical Sciences Department, University of Greenwich, U.K.

A. Bejan, Department of Mechanical Engineering and Materials Science, Duke University, U.S.A.

Y. Benveniste, Faculty of Engineering, Tel-Aviv University, Israel

W. S. Chan, Mechanical and Aerospace Engineering, University of Texas at Arlington, U.S.A.

C. K. Chao, Department of Mechanical Engineering, National Taiwan University of Science and Technology, Taiwan

J. C. Chen, Department of Mechanical Engineering, National Central University, Taiwan

J. T. Chen, Department of Harbor and River Engineering / Department of Mechanical and Mechatronic Engineering, Taiwan Ocean University, Taiwan

T. Y. Chen, Department of Civil Engineering, National Cheng Kung University, Taiwan

H. C. Cheng, Department of Aerospace and Systems Engineering, Feng Chia University, Taiwan

H. D. Cheng, Department of Civil Engineering, University of Mississippi, U.S.A.

M. Daniel, Department of Mechanics, Biomechanics and Mechatronics, Czech Technical University in Prague, Czech Republic

V. M. Fomin, Russian Academy of Sciences, Novosibirsk, Russia

H. Gao, School of Engineering, Brown University, U.S.A.

S. S. Hsieh, Department of Mechanical and Electro-Mechanical Engineering, National Sun Yat-sen University, Taiwan

C. Y. Huang, Department of Power Mechanical Engineering, National Tsing Hua University, Taiwan

M. Iguchi, Division of Materials Science and Engineering, Graduate School of Engineering, Hokkaido University, Japan

A. M. Korsunsky, Department of Engineering Science, Oxford University, U.K.

C. C. Lee, Department of Mechanical Engineering, Chung Yuan Christian University, Taiwan

C. A. Lin, Department of Power Mechanical Engineering, National Tsing Hua University, Taiwan

D. S. Liu, Department of Mechanical Engineering, National Chung Cheng University, Taiwan

C. C. Ma, Department of Mechanical Engineering, National Taiwan University, Taiwan

R. Poole, School of Engineering, University of Liverpool, U.K.

Y. L. Shen, Department of Mechanical Engineering, University of New Mexico, U.S.A.

Y. C. Shiah, Department of Aeronautics and Astronautics, National Cheng Kung University, Taiwan

T. E. Tezduyar, Department of Mechanical Engineering, Rice University, U.S.A.

T. C. T. Ting, Division of Mechanics and Computation, Stanford University, U.S.A.

J. L. Tsai, Department of Mechanical Engineering, National Chiao Tung University, Taiwan

M. Y. Tsai, Department of Mechanical Engineering, Chang Gung university, Taiwan

T. Wang, Department of Mechanical Engineering, University of New Orleans, U.S.A.

W. F. Wu, Department of Mechanical Engineering, National Taiwan University, Taiwan

R. J. Yang, Department of Engineering Science, National Cheng Kung University, Taiwan

G. Q. Zhang, Delft Institute of Microsystems and Nanoelectronics, Delft University of Technology, The Netherlands

\section{Executive Editor:}

H. Y. Tsai, Department of Power Mechanical Engineering, National Tsing Hua University, Hsinchu, Taiwan

\section{Abstracted/indexed in:}

SCI Expanded; Engineering Index (EI Compendex); Current Content; Research Alert; International Aerospace Abstract; Cambridge Scientific Abstracts; Chemical Abstracts Service; Advanced Polymers Abstract; Aluminum Industry Abstracts; Composites Industry Abstracts; Computer and Information Systems Abstracts Journal; Corrosion Abstracts; Earthquake Engineering Abstracts; Electronics and Communications Abstracts Journal; Engineered Materials Abstracts; Environmental Engineering Abstracts (Online Edition); Materials Business File; METADEX; World Ceramics Abstracts (Online); Environmental Science and Pollution Management; Solid State and Superconductivity Abstracts.

\section{Publication Office:}

The Society of Theoretical and Applied Mechanics, R.O.C.

Department of Power Mechanical Engineering, National Tsing Huang University, No. 101, Sec. 2, Kuangfu Rd., Hsinchu 300, Taiwan, R.O.C.

Subscription Information: For general price and subscription enquiries, please contact Cambridge University Press:

For United Kingdom, Europe and Rest of the World: Cambridge University Press

The Edinburgh Building

Shaftesbury Road

Cambridge CB2 8RU, United Kingdom

Phone: +44-(0)-1223-326070

Fax: +44-(0)-1223-325150

Email: journals@cambridge.org

For the United States, Canada and Mexico:

Cambridge University Press

100 Brook Hill Drive

West Nyack, NY 10994-2133, USA

Phone: $+1-845-353-7500$

Toll free: $+1-800-872-7423$

Fax: +1-845-353-4141

Email: subscriptions_newyork@cambridge.org

Visit the Journal of Mechanics online at: http://journals.cambridge.org/jom

\section{Copyright (C) 2015 The Society of Theoretical and Applied Mechanics, R.O.C.}

